\title{
FORMULASI EKSTRAK KULIT BUAH NAGA MERAH (Hylocereus polyrhizus) SEBAGAI PEWARNA ALAMI DALAM SEDIAAN LIPSTIK
}

\author{
Yulyuswarni \\ Jurusan Farmasi Politeknik Kesehatan Tanjungkarang
}

\begin{abstract}
Abstrak
Hasil pengawasan yang dilakukan oleh BPOM selama bulan Januari-Juni tahun 2016 menemukan 43 item kosmetika mengandung bahan berbahayaantara lain merkuri, hidrokuinon, asam retinoat, deksametason, klindamisin, serta bahan pewarna merah K3 dan merah K10. Kosmetika yang mengandung bahan pewarna berbahaya beberapa diantaranya adalah lipstik. Penggunaan zat warna berbahaya dalam sediaan lipstik sendiri dapat menjadi pemicu masalah kesehatan khususnya pada kulit. Salah satu alternatif yang bisa dilakukan adalah dengan menggunakan pearna alami dalam sediaan lipstik. Kulit buah naga merah (Hylocereus polyrhizus) merupakan tanaman yang mengandung pigmen warna betalain yang bisa dimanfaatkan sebagai pewarna alami dalam formulasi sediaan lipstik). Penelitian ini bertujuan untuk membuat sediaan lipstik menggunakan ekstrak kulit buah naga merah (Hylocereus polyrhizus) sebagai pewarna alami dengan konsentrasi $17.5 \%, 20 \%, 22,5 \%$ dan $25 \%$, dan mengetahui mutu sediaan lipstik berupa organoleptis, homogenitas, $\mathrm{pH}$, titik lebur, daya lekat, iritasi serta kesukaan panelis. Penelitian yang dilakukan bersifat eksperimental kualitatif dengan menganalisis hasil evaluasi sediaan lipstik dengan cara membandingkan data yang diperoleh dengan persyaratan sediaan lipstik dan ANAVA. Hasil penelitian menunjukkan bahwa sediaan lipstik ekstrak kulit buah naga merah (Hylocereus polyrhizus) dengan variasi konsentrasi memiliki peningkatan warna yaitu dari cokelat muda menjadi cokelat tua, berbau khas, dan memiliki konsistensi setengah padat cenderung keras. Seluruh formula tidak homogen, memiliki pH antara 5.3-6,1. Titik lebur $53^{\circ} \mathrm{C}-55.3^{\circ} \mathrm{C}$, perbedaan titik lebur berbeda secara bermakna antara F0 dengan F3 dan F4, kemudian F1 dengan F2, F3, dan F4. Seluruh formula memiliki daya lekat yang kurang baik dan tidak menyebabkan iritasi. Uji kesukaan tidak dilakukan karena tidak ada formula yang memenuhi semua syarat mutu sediaan lipstik
\end{abstract}

Kata Kunci :Lipstik, Ekstrak, kulit buah naga merah

\section{FORMULATION OF BRAIN LEATHER LEATHER EXTRACTS (Hylocereus polyrhizus) AS NATURAL DYES IN LIPSTICAL SUPPLY}

\begin{abstract}
Supervision conducted by BPOM during January-June 2016 found 43 items of cosmetics containing hazardous materials among others mercury, hydroquinone, retinoic acid, dexamethasone, clindamycin, as well as red and K3 red colorants K10. Cosmetics containing some harmful dyes are lipsticks. The use of harmful dyes in their own lipstick preparations can be a trigger for health problems especially on the skin. One alternative that can be done is to use natural pearna in the preparation of lipstick. Red dragon fruit skin (Hylocereus polyrhizus) is a plant containing color pigment betalain which can be utilized as a natural dye in the formulation of lipstick preparations). This study aimed to make lipstick preparation using red dragon fruit extract (Hylocereus polyrhizus) as a natural dye with concentration of $17.5 \%, 20 \%, 22.5 \%$ and $25 \%$, and to know the quality of lipstick preparation in the form of organoleptis, homogeneity, $\mathrm{pH}$, melting point, adhesiveness, irritation and panelist preferences. The experimental study was qualitative experimental by analyzing the results of lipstick preparation evaluation by comparing the data obtained with lipstick and ANAVA preparation requirements. The results showed that the preparation of red dragon fruit lipstick extract (Hylocereus polyrhizus) with variation of concentration has increased the color that is from light brown to dark brown, typical smell, and has a solid consistency of semi-solid tends. The whole formula is not homogeneous, has a $\mathrm{pH}$ between 5.3-6.1. Melting point 530C-55.30C, melting point difference differed significantly between F0 with F3 and F4, then F1 with F2, F3, and F4. All formulas have poor adhesion and do not cause irritation. The favorite test is not performed because there is no formula that meets all lipstick preparation quality requirements.
\end{abstract}

Keywords: Lipstick, Extract, red dragon fruit skin

Korespondensi : Siti Julaiha, Jurusan Farmasi Politeknik Kesehatan Tanjungkarang, Jl Soekarno Hatta No.1 Bandar Lampung, Mobile 081369025859, e-mail : 


\section{Pendahuluan}

Lipstik adalah produk kosmetik dekoratif yang paling luas digunakan. Lipstik/pewarna bibir merupakan sediaan kosmetika yang digunakan untuk mewarnai bibir dengan sentuhan artistic sehingga dapat meningkatkan estetika dalam tata rias wajah (Depkes RI, 1985). Bibir memiliki anatomis dan fisiologisnya agak berbeda dari kulit bagian badan lainnya, misalnya stratum corneum-nya sangat tipis dan dermisnya tidak mengandung kelenjar keringat maupun kelenjar minyak, sehingga mudah kering dan pecah-pecah terutama jika dalam udara yang dingin dan kering.(Tranggono\& Latifah, 2007).

Selama semester I tahun 2016, Badan POM menemukan 43 (empatpuluhtiga) itemkosmetikamengandungbahanberbahaya.Ba han berbahaya yang teridentifikasi dalam produk kosmetika tersebut antara lain merkuri, hidrokuinon, asamretinoat, deksametason, klindamisin, serta bahan pewarna merah K3 dan merah K10. Kedua zat warna ini sering digunakan sebagai pewarna pada kosmetik dekoratif seperti lipstik, eye shadow, blush on.(BPOM RI, 2016). Merah K10 (Rhodamin B) dan merah K3 (methanyl yellow) digunakan pada industri tekstil dan kertas. Selain mengakibatkan iritasi pada kulit. (Pusat Informasi obat dan Makanan, 2014) kedua pewarna ini juga bersifat karsinogenik(BPOM RI, 2016)

Seiring dengan perkembangan gaya hidup back to nature, maka zat warna alami mulai menjadi pilihan untuk menghindari penggunaan pewarna sintetik yang berbahaya. Salah satu pewarna alami yang potensial untuk dikembangkan adalah betasianin yang berasal dari buah naga merah (Hylocereuspolyrhizus). Buah naga merah mengandung betasianin yang berfungsi sebagai anti oksidan dan pewarna alami.Kulit buah naga berjumlah $22 \%$ dari berat buah naga, dan sering kali hanya dibuang sebagai sampah (Jamilah, et all, 2011). Kulit buah naga memiliki potensi anti oksidan lebih besar dari pada buahnya (Darmawi dalam Farida 2015).

Handayani, Prima dan Astri (2012) menggunakan ekstrak kulit buah naga sebagai pewarna makanan sedangkan Pribadi, Sukatiningsih dan Sari,(2014) menggunakan ekstrak kulit buah naga sebagai pewarna dalam tablet effervescent. Handayani dan Haryanto S., (2011)merancang formulasi sediaan lipstik dari perasan buah naga sebagai pewarna alami. Menurut Hotnida (2015) dalam penelitiannya formulasi lipstik dengan konsentrasi ekstrak kulit buah naga merah $5 \%, 10 \%$, dan $15 \%$, ternyata lipstik dengan konsentrasi $15 \%$ memberikankan hasil yang baik, namun warna dari ekstrak kulit buah naga merah yang ditimbulkan kurang jelas, hal ini mungkin disebabkan karena konsentrasi ekstrak kulit buah naga merah yang digunakan kurang tinggi.

Penelitian ini adalah untuk mendapatkan formulasi lipstik dari ekstrak kulit buah naga merah (Hylocereus polyrhizus) sebagai pewarna alami yang memenuhi syarat sediaan lipstik, tidak mengiritasi kulit dan disukai panelis

\section{Metode}

Kegiatan penelitian ini meliputi Penyiapan ekstrak, pembuatan formulasi sediaan lipstik serta evaluasi sediaan.

\section{Ekstraksi:}

Sebanyak $8 \mathrm{~kg}$ buah naga merah (Hylocereus polyrhizus) segar, dicuci, dikupas dan diambil kulitnya $(4,25 \mathrm{~kg})$. Kulit buah naga merahdirajang kasar kemudian maserasi menggunakan pelarut etanol 96\% selama 3 hari dan dilakukan remaserasi. Maserat yang diperoleh diuapkan dengan rotary evaporator sehingga diperoleh ekstrak kental.

Formulasi Lipstik:

Lipstik di buat sesuai prosedur kerja dengan formulasi seperti pada tabel 1 .

Nipasol sebagai pengawet dan BHT sebagai anti oksidan dilarutkan dalam propilen glikol. Tambahkan oleum ricini, paraffin likuidum dan ekstrak kental kulit buah naga merah (Hylocereuspolyrhizus), gerus homogen (massa A). Masa lilin, dan lemak seperti cera alba, carnauba wax, beeswax, lanolin, ol cacao dan setil alkohol, di lebur di atas penangas air (massa B). Setelah lebur masukkan massa B ke masa A, aduk homogen. Tunggu agak dingin baru ditambahkan oleum rosae dan tuang ke dalam alat cetak. 
Tabel 1. Formula lipstik ekstrak kulit buah naga merah (Hylocereus polyrhizus) polyrhizus)

\begin{tabular}{|l|c|c|c|c|c|}
\hline \multirow{2}{*}{ Komposisi } & \multicolumn{5}{c|}{ Komposisi (\% b/b) } \\
\cline { 2 - 6 } & $\mathrm{F} 0$ & $\begin{array}{c}\mathrm{F} 1 \\
(17,5 \%)\end{array}$ & $\begin{array}{c}\mathrm{F} 2 \\
(20 \%)\end{array}$ & $\begin{array}{l}\mathrm{F} 3 \\
(22,5 \%)\end{array}$ & $\begin{array}{l}\mathrm{F} 4 \\
(25 \%)\end{array}$ \\
\hline Ekstrak kulit buah naga merah & 0 & 17,5 & 20 & 22,5 & 25 \\
\hline Lanolin & 5 & 5 & 5 & 5 & 5 \\
\hline Ol cacao & 15 & 15 & 15 & 15 & 15 \\
\hline Setil alkohol & 2 & 2 & 2 & 2 & 2 \\
\hline Cera alba & 20 & 20 & 20 & 20 & 20 \\
\hline Carnauba wax & 5 & 5 & 5 & 5 & 5 \\
\hline Cera Flava & 5 & 5 & 5 & 5 & 5 \\
\hline Propilenglikol & 10 & 10 & 10 & 10 & 10 \\
\hline Oleum ricini & 20 & 20 & 20 & 20 & 20 \\
\hline Oleum rosae & 0,4 & 0,4 & 0,4 & 0,4 & 0,4 \\
\hline BHT & 0,1 & 0,1 & 0,1 & 0,1 & 0,1 \\
\hline Nipasol & 0,5 & 0,5 & 0,5 & 0,5 & 0,5 \\
\hline Parafin cair & $\mathrm{Ad} 100$ & $\mathrm{Ad} 100$ & $\mathrm{Ad} 100$ & $\mathrm{Ad} 100$ & $\mathrm{Ad} 100$ \\
\hline
\end{tabular}

(Sumber : Handayani (2011) dan modifikasi)

Keterangan :

Formula 0 : formula basis tanpa ekstrak

Formula 1 : formula dengan konsentrasi ekstrak kulit buah naga merah $17,5 \%$

Formula 2 : formula dengan konsentrasi ekstrak kulit buah naga merah $20 \%$

Formula 3 : formula dengan konsentrasi ekstrak kulit buah naga merah 22,5\%

Formula 4 :formula dengan konsentrasi ekstrak kulit buah naga merah $25 \%$

Evaluasi Mutu Sediaan Lipstik:

Pengujian mutu lipstik meliputi uji organoleptik (warna, konsistensi dan aroma), homogenitas (menggunakan kaca objek dan dispersi warna), $\mathrm{pH}$, titik lebur, daya lekat dan iritasi. Selanjutnya formula yang memenuhi syarat dilakukan uji kesukaan panelis

\section{Uji Organoleptik}

Uji organoleptik dilakukan dengan menggunakan pancaindra. Komponen yang dievaluasi meliputi bau, warna, konsistensi sediaan

Uji homogenitas

Uji homogenitas polesan yaitu dengan cara mengoleskan sejumlah tertentu sediaan pada kaca yang transparan. Sediaan harus menunjukkan susunan yang homogen dan tidak terlihat adanya butir-butir kasar

(Depkes RI, 1979)

Uji titik lebur

Pengujian dilakukan dengan menggunakan alat melting point apparatus. Lipstik dimasukkan dalam pipa kapiler dengan kedalaman $10 \mathrm{~mm}$. Kemudian pipa kapiler tersebut diletakkan dalam alat melting point apparatus dengan posisi yang sesuai. Suhu pada saat lipstik mulai meleleh, adalah titik lebur lipstik. Titik lebur harus diatas $45^{\circ} \mathrm{C}$, dan sebaiknya diatas $50^{\circ} \mathrm{C}$ (Balsam, at all, 1972). Menurut SNI (standar nasional Indonesia) No. 16-4769-1998 persyaratan titik lebur lipstik yang tertera adalah $50^{\circ}-70^{\circ} \mathrm{C}$

\section{Uji pH}

Penentuan uji $\mathrm{pH}$ menggunakan alat $\mathrm{pH}$ meter. Sebelumnya $\mathrm{pH}$ meter dikalibrasi dengan larutan dapar pada $\mathrm{pH}$ 4-7.Sampel dibuat dengan konsentrasi $1 \%$, kemudian dicelupkan elektroda $\mathrm{pH}$ meter. Angka yang ditunjukkan oleh alat adalah $\mathrm{pH}$ sediaan lipstik. $\mathrm{pH}$ kulit berkisar antara 4,5-6,5(Tranggono \& Latifah, 2007).

\section{Uji Iritasi}

Uji yang digunakan pada uji iritasi ini adalah uji tempel terbuka (Open Patch Test). Bahan langsung diaplikasikan 2-3 kali sehari ke area yang sama pada lengan bawah bagian dalam panelis .Reaksi yang terjadi langsung di nilai. Uji ini dilakukan selama dua hari untuk setiap sediaan. Reaksi iritasi positif ditandai oleh adanya kemerahan, gatal-gatal, atau bengkak pada kulit lengan bawah bagian dalam yang diberi perlakuan. Adanya kulit merah diberi nilai (1), gatal-gatal (2), bengkak (3), dan yang 
tidak, dan menunjukkan reaksi apa-apa diberi nilai (0). (Tranggono \& Latifah, 2007).

\section{Uji Oles/Uji daya lekat}

Pengamatan dilakukan dengan secaravisual dengan cara mengoleskan lipstik pada bibir kemudian mengamati banyaknya warna yang menempel pada tekanan tertentu seperti biasanya kita menggunakan lipstik. Pemeriksaan dilakukan terhadap masingmasing sediaan yang dibuat dan di oleskan pada bibir dengan 5 kali pengolesan. Pelepasan zat warna yang baik ditunjukkan dengan banyaknya warna yang dilepaskan dan menempel dengan baik. Sedangkan sediaan dikatakan memiliki daya lekat yang tidak baik, jika warna yang menempel sedikit dan tidak merata. Daya lekat tidak baik diberi skor 1,baik diberi skor 2 dan sangat baik di beri skor 3 (Keithler, 1956 dalam Adliani dkk).

\section{Uji Kesukaan}

Uji kesukaan dilakukan untuk mengetahui tingkat kesukaan panelis terhadap warna, aroma, dan daya lekat sediaan yang telah memenuhi syarat organoleptik, homogenitas, titik lebur, $\mathrm{pH}$, daya lekat dan tidak mengiritasi. Panelis mengoleskan lipstik pada punggung tangan, kemudian panelis mengisi kuesioner yang telah disiapkan, dengan skor $1=$ tidak suka, $2=$ suka, $3=$ sangat suka .

\section{Hasil Dan Pembahasan}

Dari 4,25 kg kulit buah naga merah segar yang dimaserasi menggunakan etanol 96\% sebanyak 10 literselama 3 hari, diperoleh ekstrak kental sebanyak 185 gram. Ekstrak yang dihasilkan berwarna cokelat, $\mathrm{pH}$ asam yaitu 4.96

\section{Uji Organoleptis}

Pengujian organoleptis dilakukan dengan cara visual oleh peneliti.Variasi konsentrasi pewarna ekstrak kulit buah naga merah yang digunakan menghasilkan perbedaan warna lipstik. Lipstik dengan konsentrasi ekstrak kulit buah naga merah 17,5\% menghasilkan warna coklat muda, pada konsentrasi 20\% menghasilkan warna coklat, dan konsentrasi $25 \%$ menghasilkan warna coklat tua.Warna cokelat ini disebabkan dari warna ekstrak kulit buah naga merah (Hylocereus polyrhizus) yang berwarna cokelat..

Banyak faktor yang mempengaruhi stabilitas pigmen, antara lain $\mathrm{pH}$, temperatur, cahaya, oksigen, dan faktor lain seperti enzim dan ion logam yang dapat merusak pigmen. Umunya betalain stabil dalam kondisi asam, media bebas oksigen, dalam kondisi suhu dingin dan gelap (Azeredo 2006 dalam Faridah (2014). Senyawa betalain dapat terdegradasi karena pengaruh peningkatana suhu. Menurut Azeredo (2009) degradasi betalain meningkat akibat meningkatnya suhu. Akibat peningkatan suhu betalain terdegradasi melalui isomerisasi, dekarboksilasi dan terurai menghasilkan secara bertahap reduksi warna merah dan akhirnya menjadi coklata muda. Dehidrogenasi mengarah ke formasi neo betanin berwarna kuning. Dekarboksilasi menyebabkan hypsokhromik pergeseran puncak absorbsi dari $538 \mathrm{~nm}$ menjadi $505 \mathrm{~nm}$ menghasilkan warna oranye merah. Hasil studi Altamirano dkk (1993) dalam Azeredo (2009) mengevaluasi degradasi termal betalain dalam beberapa pelarut (air/gilserol, air/propilenglikol/ dan air ethanol) pada suhu $60^{\circ} \mathrm{C}$ sampai $86^{\circ} \mathrm{C}$, diperoleh data ternyata betanin memiliki kestabilan paling rendah dalam etanol/air. Selanjutnya study Wyebraniec (2005) dalam Azeredo (2009) melaporkan degradasi betasianin dalam larutan etanol karena dekarboksilasi tunggal dan ganda yang mengakibatkan pergeseran/penguraian warna. Berbeda dengan hasil studi Faridah, Rahmi, dan Daimon (2015) pada peningkatan suhu dari $30^{\circ} \mathrm{C}, 50^{\circ} \mathrm{C}, 70^{\circ} \mathrm{C}, 100^{\circ} \mathrm{C}$ dengan pelarut etanol $60 \%$, degradasi warna baru terjadi pada suhu $50^{\circ} \mathrm{C}$ yaitu $0,28 \%$ sama dengan suhu $70^{\circ} \mathrm{C}$, sedangkan pada suhu $100^{\circ} \mathrm{C}$ degradasi terjadi $100 \%$. Berbeda dengan penelitian Azwanida, dkk, (2015), dalam penelitiannya degradasi warna merah dari betalain terjadi setelah pemanasan $80^{\circ} \mathrm{C}$, oleh karena itu memiliki potensi untuk digunakan dalam manufaktur lipstik yang membutuhkan panas sampai dengan $80^{\circ} \mathrm{C}$.

Aroma lipstik yang dihasilkan adalah berbau khas pewangi oleum rosae dikarenakan dalam formula ditambahkan pewangi lipstik yaitu oleum rosae. Konsistensi lipstik didapatkan hasil setengah padat cenderung keras dikarenakan basis lilin dan basis lemaknya lebih banyak dibandingkan dengan bahan basis lipstik yang lain

Homogenitas lipstik

Pengujian dilakukan dengan melihat wujud sediaan lipstik dan mengoleskan tipis sediaan pada kaca obyek kemudiaan diamati secara visual.Ujihomogenitas dilakukan oleh peneliti. Pada pengamatan secara visual diatas kaca obyek seluruh formula homogen, tetapi 
pada pengamatan dispersi zat warna tampak jelas bahwa sediaan tidak homogen, dimana massa ekstrak kental terkumpul di bagian bawah sediaan. Hal ini diduga terjadi karena konsentrasi ekstrak yang cukup besar sehinggan minyak yang tersedia tidak mencukupi.

Peristiwa terpisahnya pigmen dari lemak/lilin di kenal dengan istilah bleeding yang dapat di sebabkan oleh dua hal, pertama terkait kelarutan pigmen di dalam minyak dan ketidakcocokan jenis antara bahan penyusun lipstik dan yang kedua adalah perbandingan antara bahan dalam formula yang tidak seimbang (Barel,et all, 2009). Hal ini sesuai dengan pendapat Baki, et all., (2015) Pada umumnya pigment sebagai pewarna dalam formula lipstik berkisar 5\%-10\% Disamping itu juga dapat disebabkan karena pengadukan atau penggiling pigment dengan massa minyak kurang baik sehingga dispersi zat warna dalam minyak tidak homogen dan ekstrak cenderung mengumpul di bagian bawah cetakan karena efek grafitasi. Baki, et all, (2015) menyatakan bahwa langkah pertama dalam pembuatan lipstik adalah dispersi pigmen di dalam basis sehingga diperoleh massa yang seragam, dan tekstur yang halus.

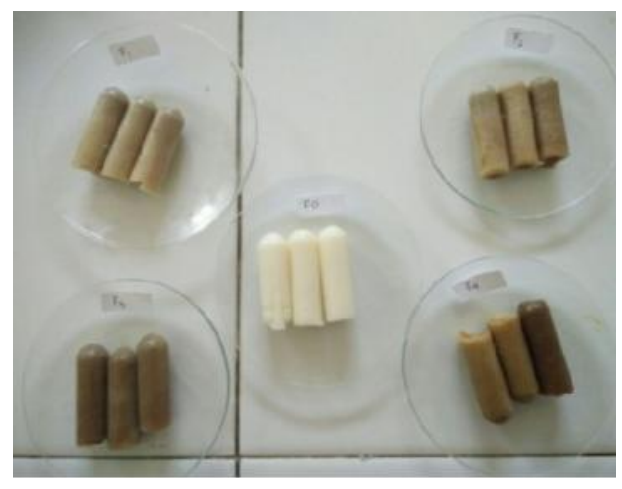

Gambar 1. Tampilan fisik lisptik kulit buah naga merah ((Hylocereus polyrhizus)

\section{Uji titik lebur}

Pengujian titik lebur dilakukan untuk mengetahui pada suhu berapa lipstik mulai melebur/meleleh, hal ini berhubungan dengan kemampuan stabilitas fisik lipstik selama penyimpanan. Menurut SNI persyaratan titik lebur lipstik adalah $50^{\circ} \mathrm{C}-70^{\circ} \mathrm{C}$, dan pada sediaan ini seluruh formula memenuhi persyaratan titik lebur yaitu antara $53^{\circ} \mathrm{C}$ sampai dengan $55.3^{\circ} \mathrm{C}$. Titik lebur sediaan meningkat dengan peningkatnya konsentrasi ekstrak. Formula F0, formula tanpa kandungan ekstrak memiliki titik lebur adalah $53^{\circ} \mathrm{C}$, sedangkan $\mathrm{F} 1=54^{\circ} \mathrm{C}$ berturut- turut $\mathrm{F} 2=54.5^{\circ} \mathrm{C} ; \mathrm{F} 3=55^{\circ} \mathrm{C}$ dan $\mathrm{F} 4=55,3^{\circ} \mathrm{C}$. Hampir sama dengan Fransisca (2011) yang mendapatkan hasil titik lebur sediaan lipstik

dari ekstrak air/perasan buah naga super merah adalah $56^{\circ} \mathrm{C}$. Sedangkan penelitian Azwanida, dkk (2014) titik lebur lipstik dari ekstrak buah naga merah di peroleh $65^{\circ} \mathrm{C}-68^{\circ} \mathrm{C}$. Berbedanya titik lebur ini dapat di sebabkan perbedaan komponen basis dari formula yang digunakan.

Tabel 2. Hasil Uji Titik Lebur

\begin{tabular}{|c|c|c|c|c|c|}
\hline \multirow{2}{*}{ No } & \multirow{2}{*}{ Formula } & \multicolumn{3}{|c|}{ Titik Lebur $\left({ }^{\mathbf{0}} \mathbf{C}\right)$} & \multirow{2}{*}{ Rerata } \\
\cline { 3 - 5 } & & $\mathbf{1}$ & $\mathbf{2}$ & $\mathbf{3}$ & \\
\hline 1 & F0 & 53 & 53 & 54 & 53 \\
\hline 2 & F1 & 53 & 53 & 54,5 & 54.5 \\
\hline 3 & F2 & 54.5 & 54. & 54 & 54 \\
\hline 4 & F3 & 55 & 54.5 & 55,4 & 54.9 \\
\hline 5 & F4 & 55 & 56 & 55 & 55.3 \\
\hline
\end{tabular}

\section{Uji $p H$}

Hasil pengujian $\mathrm{pH}$ sediaan lipstik menggunakan ekstrak kulit buah naga merah menunjukkan bahwa semakin tinggi konsentrasi ekstrak maka semakin asam $\mathrm{pH}$ yang dihasilkan dari sediaan lipstik. Karena dipengaruhi oleh $\mathrm{pH}$ asam dari ekstrak kulit buah naga merah yaitu 4,96. Hanya Formula 0 (basis atau tanpa ekstrak) yang tidak memenuhi syarat $\mathrm{pH}$ yaitu 6.6. Formula 1 sampai 4 memenuhi syarat $\mathrm{pH}$ 
evaluasi sediaan lipstik karena $\mathrm{pH}$ lipstik yang dihasilkan harus sesuai dengan $\mathrm{pH}$ fisiologis kulit bibir manusia yaitu 4,0-6,5 (Baki, et all,
(2015). Dan berdasarkan data statistik Anova tidak terdapat perbedaan secara bermakna diantara ke lima formula tersebut

Tabel 3. Hasil Uji pH

\begin{tabular}{|c|c|c|c|c|c|}
\hline \multirow{2}{*}{ No } & \multirow{2}{*}{ Formula } & \multicolumn{3}{|c|}{$\mathbf{p H}$} & \multirow{2}{*}{ Rerata } \\
\cline { 3 - 5 } & & $\mathbf{1}$ & $\mathbf{2}$ & $\mathbf{3}$ & \\
\hline 1 & F0 & 6.5 & 6.6 & 6.7 & 6.6 \\
\hline 2 & F1 & 6.3 & 6.0 & 6.2 & 6.1 \\
\hline 3 & F2 & 5.5 & 5.5 & 5.6 & 5.5 \\
\hline 4 & F3 & 5.2 & 5.2 & 5.3 & 5.2 \\
\hline 5 & F4 & 5.3 & 5.3 & 5.3 & 5.3 \\
\hline
\end{tabular}

\section{Ujian Daya lekat}

Pengujian daya lekat dilakukan oleh panelis yang terdiri dari 15 orang mahasiswi Jurusan Farmasi Poltekkes Tanjungkarang. Pengujian dilakukan dengan mengoleskan sediaan lipstik pada bibir panelis dengan 5 kali pengolesan. Hasil yang diperoleh menunjukkan bahwa pada F 4, memiliki daya lekat yang lebih baik dibandingkan F3. Meskipun tidak sampai $50 \%$ panelis menyatakan F3 maupun F4 memiliki daya lekat yang baik. Hal ini dapat dilihat dari hasil uji yang dilakukan, bahwa semakin tinggi konsentrasi ekstrak kulit buah naga merah pada sediaan lipstik semakin banyak konsentrasi ekstrak kulit buah naga merah yang menempel karena daya lekat yang baik dapat dilihat dari banyaknya warna yang dilepaskan dan menempel baik pada bibir setelah pengolesan, sedangkan pelepasan zat warna yang tidak baik ditunjukkan dengan sedikitnya warna yang dilepaskan dan menempel pada bibir (Keithler, 1956 dalam Adliani dkk)

Uji iritasi

Dari hasil pengujian yang dilakukan tidak ada reaksi yang ditimbulkan sediaan lipstik terhadap bibir panelis seperti kulit kemerahan, bengkak, maupun gatal- gatal .Hal ini membuktikan bahwa sediaan lipstik aman dan tidak mengiritasi. Hasil uji iritasi ini sesuai dengan hasil penelitian Handayani dan Haryanto S (2011).

\section{Pemenuhan uji mutu sediaan lipstik}

Dari hasil evaluasi mutu sediaan lipstik yang dilakukan ternyata tidak ada formula yang memenuhi syarat sediaan lipstik, mulai dari organoleptik, warna merah ungu betalain yang diharapkan sebagai pewarna alami sediaan lipstik tidak didapatkan. Homogenitas, titik lebur, $\mathrm{pH}$, daya lekat tidak ada yang memenuhi syarat. Hanya hasil uji iritasi yang menunjukkan $100 \%$ panelis tidak memberikan reaksi, yang berarti bahwa sediaan aman untuk digunakan. Karena tidak ada formula yang seluruhnya memenuhi syarat evaluasi mutu lipstik, maka uji kesukaan tidak dapat dilanjutkan

Kesimpulan dalam penelitian ini yaitu ekstrak kulit buah naga merah (Hylocereus polhyrhizus) yang diformulasikan ke dalam sediaan lipstik belum memenuhi seluruh persyaratan mutu sediaan lipstik, sehingga masih di perlukan pengembangan penelitian lebih lanjut

Kajian etik penelitian ini telah mendapatkan persetujuan oleh Komisi Etik Penelitian Kesehatan Poltekkes Tanjungkarang dengan no 194/EC/KEP-TJK/VIII/2017 tanggal 14 Agustus 2017

\section{DAFTAR PUSTAKA}

1. Departemen Kesehatan Republik Indonesia.1985. Formularium Kosmetika. Ditjen POM RI. Jakarta.

2. Tranggono dan Latifah, 2007. Buku Pegangan Ilmu Pengetahuan Kosmetik. Jakarta:Gramedia Pustaka Utama.

3. BPOM RI, 2016,Siaran Pers tentang Waspada Kosmetika Mengandung Bahan Berbahaya. Jakarta. Tersedia http://www.pom.go.id/mobile/index.php/vi ew/pers/310/WASPADA-KOSMETIKAMENGANDUNG-BAHAN-

BERBAHAYA-----Pilih-KosmetikaAman-untuk-Tampil-Cantik----.html bpom 2016[30 Juni 2016]

4. Departemen Kesehatan Republik Indonesia, 1979. Farmakope Indonesia, Ed Ketiga,.Ditjen POM RI. Jakarta 
5. Jamilah, et all., 2011, A. Phyico-chemical characteristic of red pitaya (Hylocereus polyrhizus) peel. International Food Research Journal 18:279-286

6. Azeredo , 2009, Betalain: propertis, sources,application and satability a review, International Journal of Food and Technology, 44 ,2365-2376

7. Azwanida, dkk, 2015, Color Stability Evaluation of Pigment Extracted from Hylocereus polyrhizus, Clitoreaternatae and Pandanus amaryll folius as Cosmetic Colorants and Premarket Survey on Customer Acceptance on Natural Cosmetic Product, Journal of Tropical Resources and Suistanable Science, Faculty of Agro Based Industry, Universiti Malaysia Kelantan, Malaysia, 3, p 61-67.

8. Baki,et all.,2015, Introduction to Cosmetic Formulation Technology, Jhon Willey \& Son, New York.

9. Handayani, dan Haryanto S.,2011 Formulasi Sediaan Lipstik menggunakan Ekstrak Buah Naga Super Merah (Hylocereus costaricencis) sebagai zat warna alami., tersedia online http://perpustakaan.fmipa.unpak.ac.id/file/ ejurnal\%20066111126.pdf[diakses 2 Mei 2017]

10. Handayani, Prima, dan Astri,2012, Pemanfaatan Kulit Buah Naga (Dragon Fruit) sebagai Pewarna Alami Makanan Pengganti Pewarna Sintetis, Jurnal Bahan Alam Terbarukan Vol 1(2) p 19-24

11. Hotnida S, 2015, Formulasi Sediaan Lipstik Menggunakan Ekstrak Kulit Buah Naga Merah (Hylocereus polyrhizus) sebagai Zat Pewarna Alami. Skripsi Sarjana, Fakultas Farmasi UTB, Lampung.

12. Barel, (Ed) at all, 2009, "Hand Book of Cosmetic Science and Technologi, Informa Healthcare, New York,

13. Pribadi,Sukatiningsih dan Sari, 2014, Formulasi Tablet Effervescent Berbahan Baku Kulit Buah Naga Merah ((Hylocereus polyrhizus) dan Buah Salam (Syzygium polyanthum [Wight.] Walp). Berkala Ilmiah Pertanian 1(4): 86-89

14. Pusat Informasi Obat dan MakananBPOM, 2014, "Penggunaan Rhodamin B pada Kosmetik", Info POM, Vol 15, No.5, hal 3-4, Jakarta bulan September -Oktober 2014 